\title{
Huaier extract exerts immunomodulatory effects by regulating serum cytokines in breast cancer
}

\author{
Li Zhang ${ }^{1 \#}$, Ning Zhang ${ }^{1 \#}$, Xinyu $\mathbf{Q u}^{1}$, Yaming Li $^{1}$, Qifeng Yang ${ }^{1,2}$ \\ ${ }^{1}$ Department of Breast Surgery, ${ }^{2}$ Pathology Tissue Bank, Qilu Hospital, Shandong University, Jinan 250012, China \\ Contributions: (I) Conception and design: Q Yang, N Zhang, L Zhang; (II) Administrative support: None; (III) Provision of study materials or \\ patients: L Zhang, X Qu, Y Li; (IV) Collection and assembly of data: N Zhang, L Zhang; (V) Data analysis and interpretation: N Zhang, L Zhang; (VI) \\ Manuscript writing: All authors; (VII) Final approval of manuscript: All authors. \\ \#These authors contributed equally to this work. \\ Correspondence to: Qifeng Yang. Department of Breast Surgery, Qilu Hospital, Shandong University, Jinan 250012, China. \\ Email: qifengy_sdu@163.com.
}

Background: Huaier extract, a traditional Chinese medicine (TCM) with a 1,600-year history, has recently become a complementary anticancer drug in China. Previous studies have demonstrated that Huaier extract has multiple anticancer effects. However, whether Huaier extract has immunomodulatory effects on serum cytokine profiles in breast cancer patients remains unknown.

Methods: Thirty-eight serum specimens were collected from 19 female breast cancer patients who were treated with Huaier extract before surgery in Qilu Hospital, and serum cytokines were analyzed by BioPlex ProTM cytokine assays. Murine breast cancer model was built to further verify the immunomodulatory effects of Huaier extract, and serum cytokine levels were detected by enzyme linked immunosorbent assay (ELISA) assay and pulmonary metastasis were counted.

Results: In this study, we found that Huaier extract significantly decreased the MCP-1, MIP-1 $\beta$ levels $(\mathrm{P}<0.05)$, and significantly increased the IL-7 levels $(\mathrm{P}<0.05)$ in breast cancer patients and a murine breast cancer model $(\mathrm{P}<0.05)$. Additionally, Huaier extract inhibited pulmonary metastasis in a murine model of breast cancer.

Conclusions: The results of this study showed that Huaier extract regulated serum cytokines levels and decreased the number of metastatic lung nodules in breast cancer. Our study also identified a serum cytokine profile, which potentially could predict disease outcome and be used to monitor the efficacy of Huaier extract treatment in breast cancer.

Keywords: Huaier extract; breast cancer; cytokine profile; Bio-Plex Pro assays

Submitted Jan 09, 2018. Accepted for publication Jun 15, 2018.

doi: $10.21037 /$ tcr.2018.06.22

View this article at: http://dx.doi.org/10.21037/tcr.2018.06.22

\section{Introduction}

Cancer is a common disease worldwide and is the second leading cause of cancer-related deaths in women (1). The precise initiation process of breast cancer is still uncertain. However, increasing evidence shows that inflammation plays an important role in tumorigenesis, tumor progression and dysfunction of immune surveillance (2). Cytokines, as inflammatory mediators, play a major role in cancer-related inflammation and appear to be consistent components of the local inflammatory microenvironment in malignant tumors (3). Cytokines are soluble small polypeptides or glycoproteins that mediate intercellular communication in all immune reactions, regulating immunity, inflammation, hematopoiesis and exerting pleiotropic effects on various cell activities (4). Many cytokines were reported to play an important role in breast cancer development in an orchestrated manner, including IL-2, IL-4, IL-6, IL-10, 
INF- $\gamma$, and TNF- $\alpha$, etc. $(5,6)$. A series of studies have demonstrated that serum levels of various cytokines were changed in cancer patients and were associated with cancer metastasis and poor prognosis in different cancers (7), indicating that serum inflammatory cytokines levels could serve as biomarkers of advanced cancer and as targets for novel therapeutic.

Cytokines are classified into two categories according to their functions: pro- and anti-inflammatory cytokines. Cytokines that promote inflammation are pro-inflammatory cytokines, whereas those that suppress the activity of proinflammatory cytokines and reduce inflammation are called anti-inflammatory cytokines (8). Inflammatory cytokines directly or indirectly interfere with each other's expression, therefore the systemic effects of cytokines seem more important than isolated effect of a certain cytokine. In the local tumor microenvironment, cytokines play their functions by modulating the balance between proand anti-inflammatory cytokines, including the balance of pro- and anti-inflammatory cytokine concentrations, cytokine receptor expressions, and state of the surrounding cells (9). Shifting the balance of pro- and anti-inflammatory cytokines in breast cancer patients might provide us with a novel treatment strategy. However, to date no systematic modelling of the systemic cytokine profile in patients with breast cancer has been developed.

Recently, Huaier extract, a traditional Chinese medicine (TCM) with a 1,600-year history, has been widely used as an alternative and complementary treatment of cancers in China (10). Promising results of the conventional treatment combined with Huaier extract have attracted increasing worldwide attention (11). Huaier extract has been reported to inhibit the development of various cancers, such as breast cancer (12), hepatocellular carcinoma (HCC) (13), pulmonary cancer (14), etc., via interfering in tumor angiogenesis and inhibiting cell proliferation, invasion and metastasis. Also, a recent clinical research study suggested that Huaier extract improves the clinical efficacy of the gelatin sponge particles-transarterial chemoembolization (GSPs-TACE) treatment as well as the mid-to-long-term survival in HCC patients (15). Additionally, Huaier extract was reported to play a regulatory role in tumor-specific immunomodulation. In our earlier studies, we have reported that Huaier extract decreased M2-polarization of macrophages and inhibited macrophage-induced angiogenesis in breast cancer (12), stimulated nitric oxide (NO) production in cholangiocarcinoma cells (16), and modulated the release of various cytokines (IFN- $\gamma$, IL-2, and IL-10) and suppressed the activation of CD4+ and CD8+ T cells in tumorbearing mice (17). Together, these results suggest that Huaier extract has an immunoregulatory effect, possibly by modulating the profile of serum cytokines in breast cancer patients to ultimately exert a protective function. However, whether Huaier extract regulates the secretion of cytokines in breast cancer patients remains largely unknown.

\section{Methods}

\section{Patients study}

\section{Participants}

A total of 19 female patients diagnosed with stages I-IV ductal invasive breast cancer, with ages between 39-70 years were included in this study. All the patients were recruited before undergoing surgery and other treatment at Qilu Hospital of Shandong University, Jinan City, Shandong Province, China. Patients with diabetes mellitus, renal and hepatic diseases were excluded from this study. The characteristics of the patients are listed in Table 1. A total of 38 serum specimens were collected from the 19 patients, including 19 serum samples obtained before Huaier treatment and 19 obtained after the treatment, which were stored at $-80{ }^{\circ} \mathrm{C}$ until used for analysis.

\section{Ethical statement}

The participants were recruited according to the protocol approved by the Ethics Committee of Scientific Research of Shandong University Qilu Hospital and the ID/number of ethical approval is KYLL-2016-221. All participants were given informed consent prior to participation and were informed as to the nature and goals of this study.

\section{Huaier granule administration}

Patients were given Huaier granule (Gold Grams; Qidong Gai Tianli Pharmaceutical Co. Ltd., Qidong, China; State Food and Drug Administration (Trial) standard YBZ04202003) orally, $20 \mathrm{~g} \times 3$ times every day, beginning from the first day in hospital and continuing until after surgery. Administration of Huaier granule would be discontinued due to death or intolerance.

\section{Sample collection}

Serum samples were obtained from cryo-preserved 
Table 1 Characteristics of breast cancer patients enrolled in this study

\begin{tabular}{|c|c|}
\hline Characteristics & $\mathrm{N}(\%)$ \\
\hline \multicolumn{2}{|l|}{ Ages (years) } \\
\hline Median [range] & $46[39-70]$ \\
\hline Weight (Kg) & $62.5( \pm 8.64)$ \\
\hline BMI $\left(\mathrm{Kg} / \mathrm{m}^{2}\right)$ & $24.53( \pm 3.59)$ \\
\hline \multicolumn{2}{|c|}{ Family history of cancer } \\
\hline Yes & $3(15.79)$ \\
\hline No & $16(84.21)$ \\
\hline \multicolumn{2}{|l|}{ Menopausal status } \\
\hline Pre-menopausal & $11(57.89)$ \\
\hline Post-menopausal & $8(42.11)$ \\
\hline \multicolumn{2}{|l|}{ Tumour size $(T)$} \\
\hline $\mathrm{T} \leq 2 \mathrm{~cm}$ & $5(26.32)$ \\
\hline $\mathrm{T}>2 \mathrm{~cm}$ & $14(73.68)$ \\
\hline \multicolumn{2}{|l|}{ Nodal status (N) } \\
\hline No & $9(47.37)$ \\
\hline $\mathrm{N} 1$ & $10(52.63)$ \\
\hline \multicolumn{2}{|l|}{ Metastasis (M) } \\
\hline MO & 18 (94.74) \\
\hline M1 & $1(5.26)$ \\
\hline \multicolumn{2}{|l|}{ ER status } \\
\hline Positive & 14 (73.68) \\
\hline Negative & $5(26.32)$ \\
\hline \multicolumn{2}{|l|}{ PR status } \\
\hline Positive & 14 (73.68) \\
\hline Negative & $5(26.32)$ \\
\hline \multicolumn{2}{|l|}{ HER-2 status } \\
\hline Positive & $12(63.16)$ \\
\hline Negative & $7(36.84)$ \\
\hline
\end{tabular}

Results are presented as the mean ( \pm standard deviation) or the number (frequency).

peripheral blood specimens. All the blood specimens were handled and processed in the same manner. Whole blood samples were collected into serum separator vacutainers without anticoagulant. After mixing by inverting the tubes a few times, blood samples were allowed to clot at room temperature for 30 to $45 \mathrm{~min}$. Sera was separated into clean polypropylene tubes by centrifugation at $1,000 \mathrm{~g}$ for $15 \mathrm{~min}$ at $4{ }^{\circ} \mathrm{C}$. All the assay samples were immediately aliquoted into single-use tubes in $40 \mu \mathrm{L}$ volume and stored at $-80{ }^{\circ} \mathrm{C}$, in order to avoid repeated freeze-thaw cycles.

\section{Bio-Plex Pro ${ }^{\mathrm{TM}}$ cytokine assays}

The Bio-Plex Pro ${ }^{\mathrm{TM}}$ (Bio-Rad Laboratories, Hercules, CA, USA) assays enable researchers to quantify multiple protein biomarkers with as little as $12.5 \mu \mathrm{L}$ serum in a single well of a 96-well plate in 3 to $4 \mathrm{~h}$. The assay was conducted following the manufacturer's introductions. After prewetting the 96-well plate with $100 \mu \mathrm{L}$ Bio-Plex wash buffer, $50 \mu \mathrm{L}$ of beads were added into the wells before starting the experiment. Then, the plate was washed twice with $100 \mu \mathrm{L}$ wash buffer. Subsequently, serum samples were diluted with the Bio-Plex sample diluent on ice and $50 \mu \mathrm{L}$ of the diluted serum samples were added into the wells of the plate, followed by incubation for $30 \mathrm{~min}$ at RT with shaking at $850 \mathrm{rpm}$. Then, after washing the plate 3 times, $25 \mu \mathrm{L}$ of the detection antibody was added and the plate was incubated for $30 \mathrm{~min}$ at RT with shaking at $850 \mathrm{rpm}$. Afterwards, the plate was washed another 3 times. Then, $50 \mu \mathrm{L}$ of streptavidin-PE was added into each well and the plate was incubated for $10 \mathrm{~min}$ at RT with shaking at $850 \mathrm{rpm}$. Next, the beads were suspended in $125 \mu \mathrm{L}$ of assay buffer and shaken at $850 \mathrm{rpm}$ for $30 \mathrm{~s}$. Eventually, the plate was read on a Bio-Plex system (Bio-Rad Laboratories).

In this study, the Bio-Plex Human 17-Plex standardized kit was used to detect interleukin (IL)-4, IL-6, IL-7, IL-8, IL-12, IL-17, granulocyte-macrophage colony stimulating factor (G-CSF), IFN- $\gamma$, GM-CSF, MCP- 1, MIP- $1 \beta$ and TNF- $\alpha$.

\section{Animal study}

\section{Murine breast cancer models}

Twenty-four 4-5-week-old BALB/c female mice were purchased from Vital River Laboratory Animal Technology Company (Beijing, China), and housed under specific pathogen free conditions for 1 week prior to experimentations. The 4T1 cells were suspended in phosphate buffered saline (PBS) at a concentration of $5 \times 10^{7}$ cells $/ \mathrm{mL}$. Then, $100 \mu \mathrm{L}$ of $4 \mathrm{~T} 1$ cell suspension was injected into the caudal vein of mice within $1 \mathrm{~h}$. After 3 days, mice were randomly divided into two groups, namely the control group and Huaier-treated group. Each mouse of the Huaier-treated group was intragastrically 
administered $100 \mu \mathrm{L}$ solution containing $50 \mathrm{mg}$ of Huaier extract every day, while the mice from the control group received $100 \mu \mathrm{L}$ water daily. The body weight of each mouse was measured every 3 days. The mice were sacrificed by cervical dislocation at the 30th day for further research.

\section{Sample collection}

Peripheral blood samples and the lungs of the mice were collected immediately after mice were sacrificed. Peripheral blood samples were collected in a clean polypropylene tube and allowed to clot at $4{ }^{\circ} \mathrm{C}$ overnight. Sera were separated by centrifugation at $1,000 \mathrm{~g}$ for $15 \mathrm{~min}$ at $4{ }^{\circ} \mathrm{C}$, and all sera samples were immediately aliquoted into single-use tubes and stored at $-80{ }^{\circ} \mathrm{C}$. Lung samples were collected and stored at $-80{ }^{\circ} \mathrm{C}$ within $30 \mathrm{~min}$.

\section{Ethical statement}

All animal protocols were conducted following institutional guidelines and protocols approved by the Animal Care and Use Committee of Qilu Hospital, Shandong University, Jinan, Shandong and the ID/number of ethical approval is KYLL-2016-221.

\section{Cell culture}

The mouse breast adenocarcinoma cell line 4T1, was obtained from American Type Culture Collection (ATCC; Manassas, VA, USA), and routinely maintained in Dulbecco's Modified Eagle's Medium (DMEM; GibcoBRL, Rockville, IN, USA) supplemented with $10 \%$ heatinactivated FBS, $100 \mathrm{U} / \mathrm{mL}$ penicillin and $100 \mu \mathrm{g} / \mathrm{mL}$ streptomycin. Cells were grown under the conditions of $5 \%$ $\mathrm{CO}_{2}$ at $37^{\circ} \mathrm{C}$.

\section{Preparation of Huaier extract}

The electuary ointment of the Huaier aqueous extract was a kind gift from Gaitianli Medicine Co., Ltd. (Jiangsu, China). After dissolving in complete medium, the Huaier electuary ointment was adequately filtered using a $0.22 \mu \mathrm{m}$ filter. The final Huaier extract solution was prepared at a concentration of $100 \mathrm{mg} / \mathrm{mL}$ for long term storage at $-20^{\circ} \mathrm{C}$.

\section{Determination of cytokine levels by enzyme linked immunosorbent assay (ELISA) measurement}

The serum concentrations of IL-7, MCP-1 and MIP-1 $\beta$ were measured using ELISA kits (Proteintech Group, Inc., Wuhan, China) following the manufacturer's instructions. Serum samples were diluted at a 1:2 ratio prior to the experiments. A $100-\mu \mathrm{L}$ volume of the standard samples and serum samples were added to the appropriate wells, and the plate was incubated for $2 \mathrm{~h}$ at $37{ }^{\circ} \mathrm{C}$ in a humid environment. Subsequently, the wells were washed, and the plate was further incubated with $100 \mu \mathrm{L}$ of the detection antibody solution for $1 \mathrm{~h}$, followed by incubation with $100 \mu \mathrm{L}$ of HRP-conjugated antibody for $40 \mathrm{~min}$ at $37^{\circ} \mathrm{C}$. Then, incubation with $100 \mu \mathrm{L}$ of TMB substrate solution for 10-30 min was performed to develop the color, and then the stop solution was added to stop the color development. Absorbance of each well was read at $450 \mathrm{~nm}$ using an Infinite M200 plate reader (Tecan US Inc, Chapel Hill, NC, USA) within $5 \mathrm{~min}$.

The standard curves of the known concentrations of recombinant human cytokines were prepared using a fourparameter logistic (4-PL) curve-fitting method, converting fluorescence units to concentrations $(\mathrm{pg} / \mathrm{mL})$. The cytokine concentrations in the serum samples were calculated from the standard curve, and the values were multiplied by the corresponding dilution factor when the samples had been diluted.

\section{Hematoxylin-eosin (HE) staining}

Lung samples were harvested for the examination of pulmonary metastasis. First, the number of tumor pulmonary metastasis foci was counted under the macroscope. Then lungs were fixed with $10 \%$ buffered formalin for $24 \mathrm{~h}$, and then decalcified in 5\% formic acid and embedded in paraffin. Serial sections at $5 \mu \mathrm{m}$ of lung samples were prepared and sections with the maximum area were stained with hematoxylin and eosin $(\mathrm{H} \& \mathrm{E})$. The stained tissues were observed and imaged under a microscope and the number of tumor metastasis foci was counted.

\section{Statistical analyses}

In this study, paired-samples $t$-test was used to determine differences in the median values for each cytokine before and after treatment with Huaier extract in breast cancer patients. Unpaired-samples $t$-test was used in the animal study to determine differences of cytokine levels between mice in the control group and mice in the Huaier-treated group. All the data was analyzed using GraphPad Prism version 5.0 (GraphPad Software, lnc., La Jolla, CA, USA). Values are expressed as the mean \pm standard deviation, and the differences were considered statistically significant if the $\mathrm{P}$ value was less than 0.05 . 
Table 2 Serum cytokines profiles in the study's participants

\begin{tabular}{lccc}
\hline Cytokine & Pre-receiving Huaier & Post-receiving Huaier & P value \\
\hline IL-4 & $0.62 \pm 0.31$ & $0.76 \pm 0.34$ & 0.2603 \\
IL-6 & $1.65 \pm 1.72$ & $1.33 \pm 0.53$ & 0.828 \\
IL-7 & $1.95 \pm 0.80$ & $2.45 \pm 1.02$ & 0.0496 \\
IL-12 & $4.05 \pm 3.15$ & $5.10 \pm 3.40$ & 0.0562 \\
IL-17 & $8.96 \pm 3.93$ & $8.56 \pm 3.23$ & 0.6664 \\
G-CSF & $5.54 \pm 2.99$ & $6.98 \pm 3.56$ & 0.0994 \\
IFN- $\gamma$ & $20.69 \pm 12.30$ & $26.16 \pm 15.05$ & 0.1891 \\
MCP-1 & $12.10 \pm 19.36$ & $6.38 \pm 4.89$ & 0.001 \\
MIP-1 $\beta$ & $65.53 \pm 31.33$ & $42.24 \pm 16.51$ & 0.0001 \\
TNF- $\alpha$ & $5.26 \pm 2.58$ & $6.02 \pm 2.91$ & 0.2567 \\
\hline
\end{tabular}

Results are presented as the mean \pm standard deviation. Unit for all the cytokines measured was pg/mL. IL, interleukin; G-CSF, granulocyte colony-stimulating factor; IFN- $\gamma$, interferon-gamma; MCP-1, monocyte chemoattractant protein-1; MIP-1 $\beta$, macrophage inflammatory protein; TNF, tumor necrosis factor.

\section{Results}

\section{Huaier extract regulated human serum cytokine profiles}

The serum concentration of IL-4, IL-6, IL-7, IL-12, IL-17, G-CSF, IFN- $\gamma$, GM-CSF, MCP-1, MIP- $1 \beta$ and TNF were compared among sera collected from breast cancer patients before and after treatment with Huaier and the data are presented in Table 2 and Figure 1. Serum MCP-1 and MIP$1 \beta$ levels in patients treated with Huaier were $6.38 \pm 4.89$ and $42.24 \pm 16.51 \mathrm{pg} / \mathrm{mL}$, respectively, which were significantly decreased $(\mathrm{P}<0.05)$ compared to their paired levels in untreated sera, namely $12.10 \pm 19.36$ and $65.53 \pm 31.33 \mathrm{pg} / \mathrm{mL}$ for MCP-1 and MIP-1 $\beta$, respectively. At the same time, the level of serum IL-7 was significantly increased from $1.95 \pm 0.80$, before Huaier treatment, to $2.45 \pm 1.02 \mathrm{pg} / \mathrm{mL}$ after Huaier treatment $(\mathrm{P}<0.05)$. However, the differences in the serum levels of IL-4, IL-6, IL-12, IL-17, G-CSF, GM-CSF, IFN- $\gamma$, TNF- $\alpha$ were not statistically significant $(\mathrm{P}>0.05)$.

In conclusion, Huaier Extract might play an important role in shifting the balance between pro- and antiinflammatory cytokines by promoting the secretion of IL-7 and reducing pro-inflammatory cytokines serum levels, such as MCP-1 and MIP- $1 \beta$ in patients with breast cancer. The effect of Huaier Extract on the level and pattern of serum cytokines may serve as novel therapeutic strategy in breast cancer patients.

\section{Huaier extract regulated serum IL-7, MCP-1 and MIP- $1 \beta$ levels in a murine breast cancer model}

To further examine the regulatory effects of Huaier extract on serum cytokines levels in breast cancer, we investigated the expressions of serum IL-7, MCP- 1 , and MIP- $1 \beta$ in a murine model of breast cancer using ELISA analysis. The serum concentrations of IL-7, MCP-1 and MIP$1 \beta$ are compared among sera collected from mice in nontreated control group and the Huaier-treated group in Figure 2. The serum level of IL-7 in the Huaier-treated group was significantly increased compared with the level in the control group $(\mathrm{P}<0.05)$ (Figure $2 A$ ), whereas serum levels of MCP-1 and MIP-1 $\beta$ were significantly decreased $(\mathrm{P}<0.05)$ (Figure 2B,C). These results are consistent with those found in breast cancer patients above.

\section{Profile of Huaier-regulated cytokines exerted a protective effect on mice with breast cancer}

MCP-1, MIP-1 $\beta$ and IL-7 have been reported to be associated with cancer metastasis and poor prognosis in various cancers (18-24). Accordingly, a murine model of breast cancer was developed to study the in vivo effects of the Huaier extract-induced changes in the cytokines profile on breast cancer in mice. The mice body weight and number of pulmonary metastasis were recorded and analyzed. As 

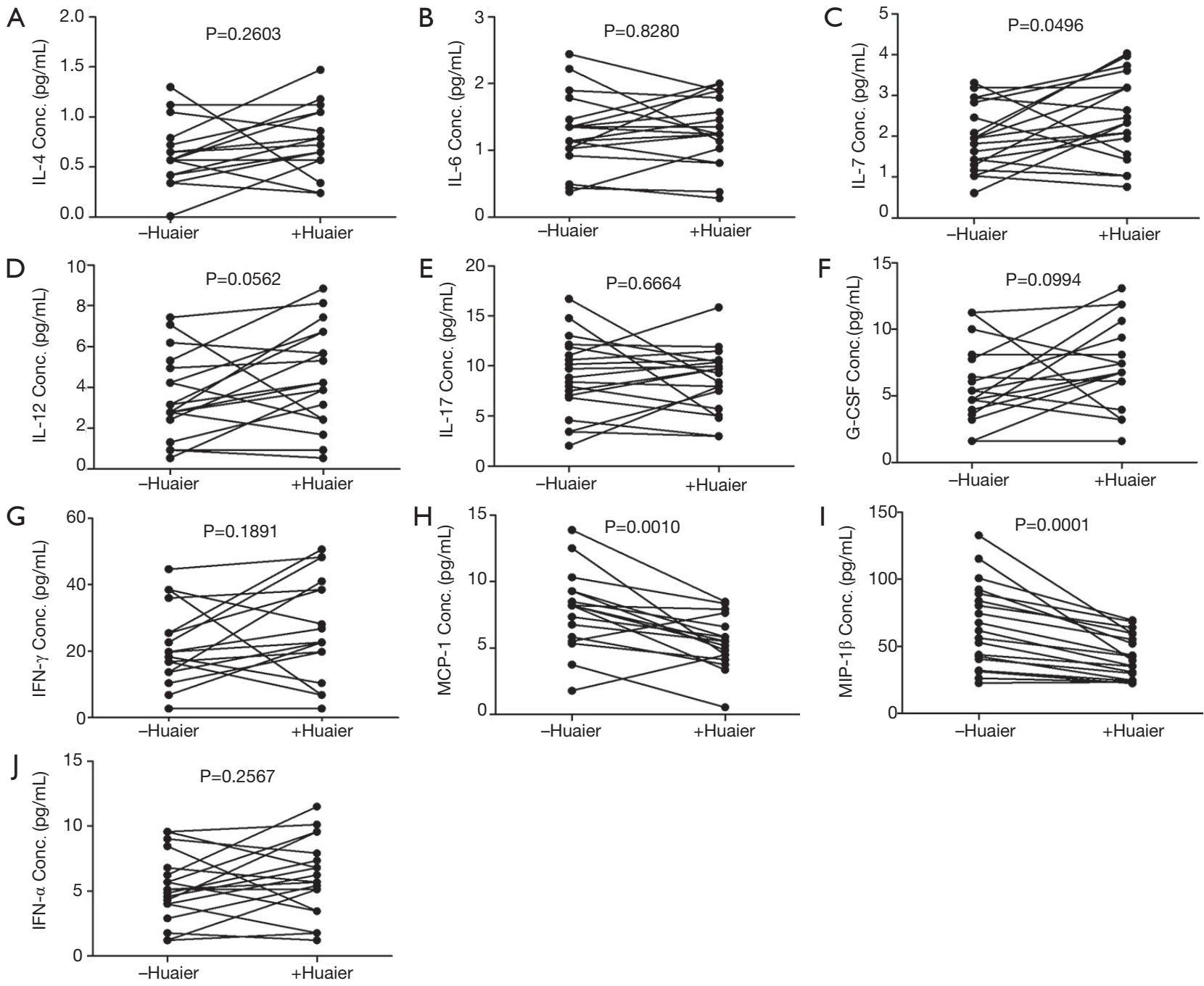

Figure 1 Huaier extract regulated human serum cytokine profiles. Changes of the cytokines profiles induced by Huaier extract in human breast cancer patients were determined using the Bio-Plex Pro ${ }^{\mathrm{TM}}$ cytokine assays. (A) Changes of IL-4; (B) IL-6; (C) IL-7; (D) IL-12; (E) IL-17; (F) G-CSF; (G) IFN- $\gamma$; (H) MCP-1; (I) MIP-1 $\beta$, and (J) TNF- $\alpha$ were analyzed (n=19 in - Huaier group or + Huaier group; Student $t$-test). Conc., concentration.
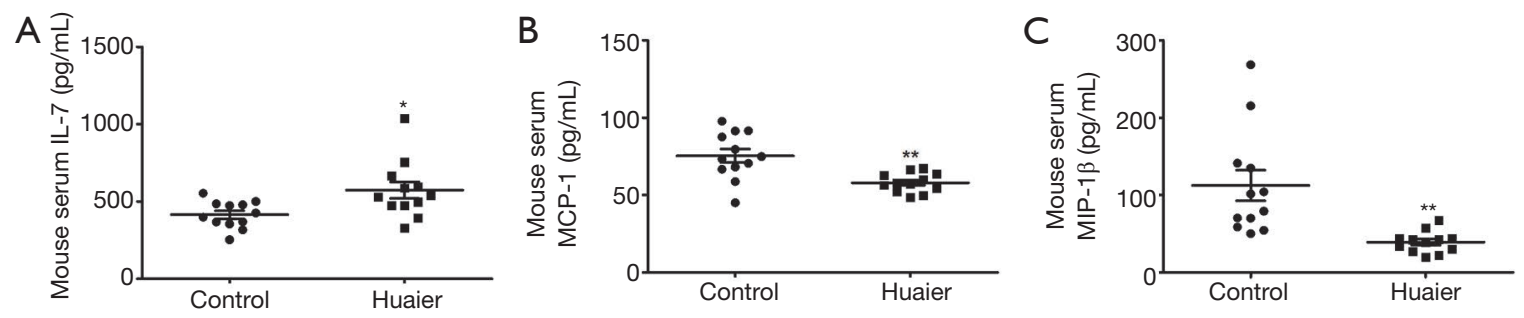

Figure 2 Huaier extract regulated serum IL-7, MCP-1 and MIP-1 $\beta$ levels in a mouse breast cancer model. Mice injected with 4T1 breast cancer cells via caudal vein were pre-treated with $100 \mu \mathrm{L}$ of PBS or Huaier extract $(50 \mathrm{mg})$ every day. Then, the mice were sacrificed, and serum samples were collected at the 30th day. (A) Expressions of IL-7, (B) MCP-1 and (C) MIP-1 $\beta$ in sera were determined by ELISA ( $\mathrm{n}=12$ in control group or Huaier group; Student $t$-test; $\left.{ }^{*}, \mathrm{P}<0.05 ;{ }^{* *}, \mathrm{P}<0.01\right)$. 
shown in Figure 3A, Huaier extract significantly attenuated the loss of body weight in breast cancer mice. The number of pulmonary metastasis foci counted macroscopically and microscopically were significantly decreased in the Huaiertreated group compared with the control group $(\mathrm{P}<0.05)$ (Figure $3 B, C$ ). In addition, the $\mathrm{H} \& \mathrm{E}$ histological staining of the lung samples (Figure $3 D$ ) revealed that considerably fewer and smaller metastasis foci and more normal pulmonary alveolar structures were found in the lung specimens of Huaier-treated mice. Thus, the results above demonstrated that Huaier extract has a protective effect on mice with breast cancer.

\section{Discussion}

Huaier extract has been shown to exert multiple antitumor and immunoregulatory effects. As demonstrated in a series of basic and clinical research studies, Huaier extract could inhibit development of many cancers, such as breast cancer (18), HCC $(13,17)$, lung cancer (14), etc. Also, Huaier extract was reported to regulate immune cells and the secretion of cytokines, such as INF- $\gamma$, IL-2, and IL$10(12,17)$, TNF- $\alpha$, IL-6, IL-1 $\beta$ (11). In this study, Huaier extract was found to significantly decrease the serum level of the chemokines MCP-1, and MIP- $1 \beta$ and significantly increase the serum level of the cytokine IL-7 in breast cancer patients. Additionally, similar results were found in a murine breast cancer model, further confirming the regulatory functions of Huaier extract on serum inflammatory cytokines.

Breast cancer is the second leading cause of cancerrelated deaths in women worldwide. The process whereby breast cancer is initiated remains uncertain, Although hypotheses have emerged suggesting that inflammation and cytokines played an important role in mediating the initiation, angiogenesis and progression of breast cancer (19). Cytokines that regulate the inflammatory tumor microenvironment are divided into two classes, namely the pro-inflammation cytokines, such as MCP-1, MIP-1 $\beta$ in our study, and anti-inflammation cytokines, like IL-7 for example. When the balance of pro- and anti-inflammatory cytokines is disrupted, the inflammatory environment would contribute to tumorigenesis. Disruption of the balance of serum cytokines is associated with cancer metastasis and poor prognosis in breast cancer patients.

MCP-1, also called Chemokine (C-C motif) ligand 2 (CCL2), a chemokine with potent monocyte chemotactic activity, is produced by tumor cells and stromal cells, such as fibroblasts, endothelial cells, lymphocytes, macrophages, etc. (20). Accumulating evidence indicates that MCP-1 plays a key role in all stages of tumor developments (10). Tumor associated macrophages (TAMs) attracted by MCP1 are essential in promoting chronic inflammation, tumor cell invasion, angiogenesis and metastasis (21). Serum levels of MCP-1 were reported to be positively correlated with tumor stage and grade in various cancers, such as breast cancer and colorectal cancer (22). In breast cancer patients, high expression of MCP-1 is also correlated with high tumor grade, lymph node metastasis, and poor prognosis (23), suggesting that MCP-1 could be a potential therapeutic target in breast cancer treatment. In this study, Huaier extract decreased the serum level of MCP-1 and thus might have reduced the number of TAMs infiltrating in the tumor environment considering that MCP-1 can accelerate breast cancer metastasis by promoting angiogenesis $(23,24)$, the reduction of serum MCP-1 induced by Huaier extract might inhibit breast cancer metastasis, as described in this study.

Macrophage inflammatory protein MIP- $1 \beta$ is a critical pro-inflammatory chemokine in the induction of inflammation and regulation of tissue homeostasis $(25,26)$. MIP $-1 \beta$ is produced by monocytes and activated T/B cells and directs the migration of monocytes, $\mathrm{T}$ cells and inflammatory cells into inflamed tissues (27) and recruits immature dendritic cells (DCs) and other lymphocytes into the tumors (28). A recent study demonstrated that MIP$1 \beta$ can promote cancer initiation (29) and act as a potential predictive marker for survival of cancer patients (30). Also, increasing evidence indicates that the serum level of MIP- $1 \beta$ is increased in carcinoma patients (31) and overexpression of MIP-1 $\beta$ is positively significantly associated with later tumor stage, and more metastasis in cancers (25). Regarding breast cancer, MIP-1 $\beta$ promoted breast cancer cell invasion and metastasis by upregulating the myosin IIIA (MYO3A) gene expression within cancer cells, which provided an opportunity to devise potential efficient anti-metastatic strategies for breast cancer clinical management (32). Noteworthy, in this study, the Huaier extract decreased the serum MIP-1 $\beta$ level and inhibited lung metastasis in mice, which is consistent with previous studies showing inhibitory effects of Huaier extract on breast cancer metastasis (33). Herein, we can surmise that Huaier extract suppresses breast cancer metastasis through the downregulation of the serum MIP-1 $\beta$ level, but further research should be conducted to verify such conjecture.

One of the main reasons for tumor progression is 

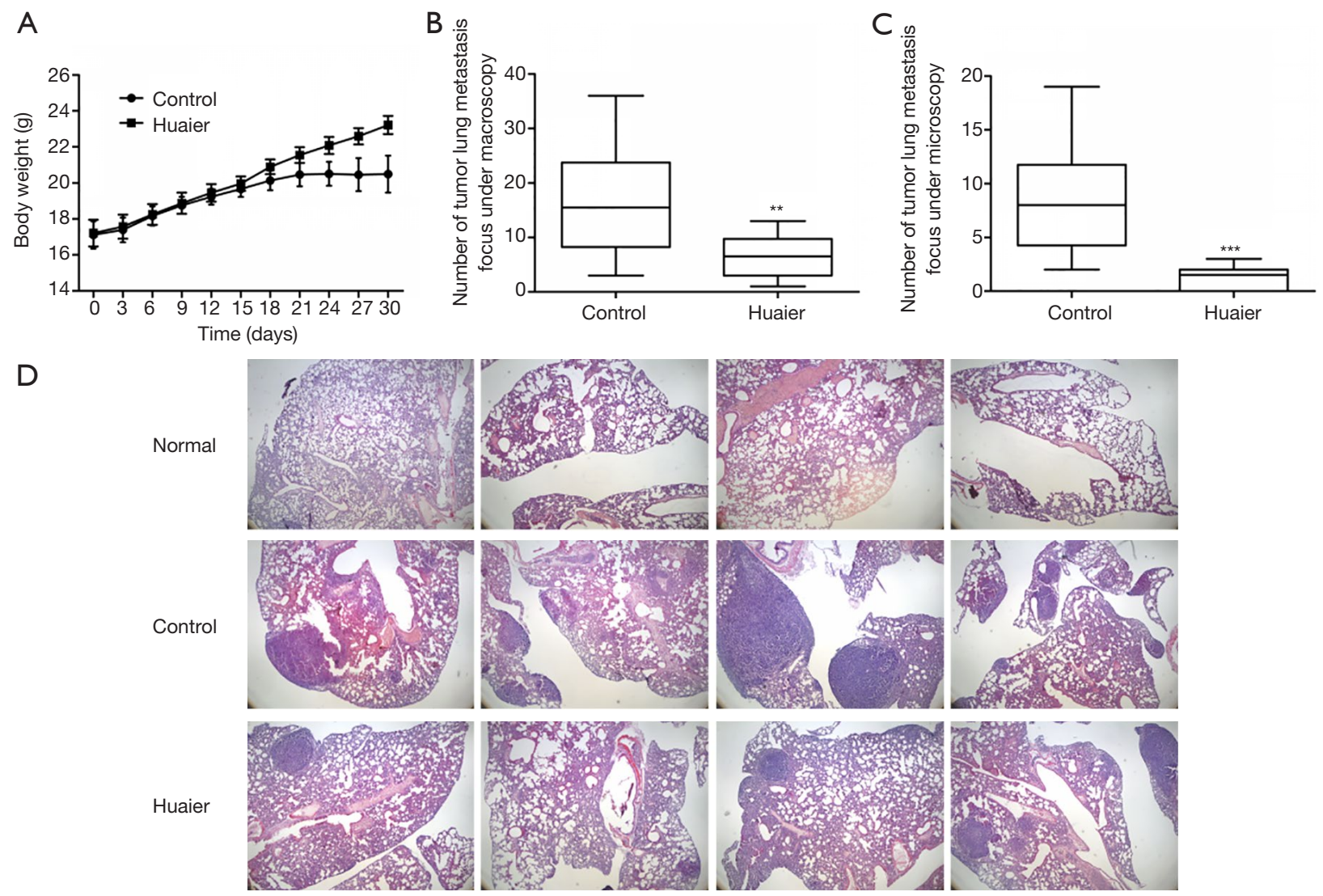

Figure 3 Huaier extract had a protective effect in breast cancer mice. Mice were sacrificed on day 30 after Huaier extract treatment. (A) Body weight was measured every 3 days during the experiment; (B) the number of lung metastases observed macroscopically and (C) under the microscope was counted and analyzed; (D) sections of paraffin-embedded lung tissues were stained with H\&E. The original amplification was $20 \times\left(\mathrm{n}=12\right.$ in control group and Huaier group; Student's $t$-test; ${ }^{* *}, \mathrm{P}<0.05$; $\left.{ }^{* * *}, \mathrm{P}<0.01\right)$.

immunosuppression (34), which is characterized by lower $\mathrm{T}$ cell counts, more exhausted cytotoxic $\mathrm{T}$ lymphocytes (CTLs), T helper cell type 2 (Th2) and macrophages (M2), rather than effector immune cells in the tumor microenvironment (35). Even worse, more T regulatory (Treg) cells and myeloid-derived suppressor cells (MDSCs) gather together in the tumor site to inhibit the effector immune responses. IL-7, a non-hematopoietic cell-derived cytokine, plays an essential role in the adaptive immune system by contributing to the development of human $\mathrm{T}$ cells $(36,37)$ and B cells (38). In addition, a substantial amount of evidence showed that IL-7 can promote lymphocyte development in the thymus (39), maintain the survival and proliferation of both naive and memory $\mathrm{T}$ cells, and modulate $\mathrm{T}$ cell homeostasis in the periphery by activating intracellular signal pathways (40). The above evidence showed that IL-7 can improve T cell function, reconstruct the immune system and antagonize immunosuppression, making it an ideal target used to enhance the immune function of the cancer patients (41). A series of preclinical trials has also shown that IL-7 can prolong the survival of tumor-bearing hosts in several tumor models, such as breast cancer (42), melanoma (43), lung cancer (44), etc. In our study, the Huaier extract induced an increase in the IL-7 serum level, which suggests that Huaier extract can promote tumor immunity via modulating the level of serum IL-7. However, further basic research is urgently needed to gain complete understanding of the complex mechanisms and interactions of Huaier extract, IL-7 and tumor immunity.

On the other hand, IL-7 was reported to directly promote cell proliferation, invasion and migration of breast cancer (45), lung cancer (46), bladder cancer and prostate 
cancer (47) cells. The pro-tumor function of IL-7 might be associated with the expression of the functional IL-7 receptor (IL-7R) in some solid tumors. Thus, it is necessary to detect the IL-7R expression before analyzing the effects of the elevated serum IL-7 level. These contrasting effects of increased serum IL-7 level on cancer cells also illustrate the point that the ultimate effect of cytokines should be viewed as the sum of all their effects, including pro- or antitumor effects. More importantly, the function of isolated cytokine is less relevant than that of systemic cytokines.

\section{Conclusions}

In conclusion, the results of this study suggest that Huaier extract has an immunoregulatory function and altered serum IL-7, MCP-1, and MIP-1 $\beta$ levels both in breast cancer patients and in a murine breast cancer model. Consistent with previous research studies, the results of our study using the murine breast cancer model showed that Huaier extract attenuates breast cancer metastasis symptoms. Moreover, the systemic cytokine profiles and the balance of pro-/antiinflammation cytokines induced by Huaier extract in breast cancer patients could provide a novel treatment strategy.

\section{Acknowledgments}

Funding: This work was supported by the National Natural Science Foundation of China (No. 81272903; No. 81672613), the Key Research and Development Program of Shandong Province (No. 2016GGE2775, 2015GSF118093), and the Special Support Plan for the National High Level Talents ("Ten Thousand Talents Program") to Qifeng Yang, and the National Natural Science Foundation of China (NO. 81502285) and China Postdoctoral Science Foundation to Ning Zhang.

\section{Footnote}

Conflicts of Interest: All authors have completed the ICMJE uniform disclosure form (available at http://dx.doi. org/10.21037/tcr.2018.06.22). The authors have no conflicts of interest to declare.

Ethical Statement: The authors are accountable for all aspects of the work in ensuring that questions related to the accuracy or integrity of any part of the work are appropriately investigated and resolved. The study was conducted in accordance with the Declaration of Helsinki (as revised in 2013). The participants were recruited according to the protocol approved by the Ethics Committee of Scientific Research of Shandong University Qilu Hospital and the ID/number of ethical approval is KYLL-2016221. All participants were given informed consent prior to participation and were informed as to the nature and goals of this study.

Open Access Statement: This is an Open Access article distributed in accordance with the Creative Commons Attribution-NonCommercial-NoDerivs 4.0 International License (CC BY-NC-ND 4.0), which permits the noncommercial replication and distribution of the article with the strict proviso that no changes or edits are made and the original work is properly cited (including links to both the formal publication through the relevant DOI and the license). See: https://creativecommons.org/licenses/by-nc-nd/4.0/.

\section{References}

1. Altekruse S, Kosary C, Krapcho M, et al. SEER cancer statistics review, 1975-2007. 2010.

2. Douglas H, Weinberg RA. Hallmarks of cancer: the next generation. Cell 2011;144:646-74.

3. Grivennikov SI, Greten FR, Karin M. Immunity, inflammation, and cancer. Cell 2010;140:883-99.

4. Whiteside TL. Inhibiting the inhibitors: evaluating agents targeting cancer immunosuppression. Expert Opin Biol Ther 2010;10:1019-35.

5. Carpi A, Nicolini A, Antonelli A, et al. Cytokines in the management of high risk or advanced breast cancer: an update and expectation. Curr Cancer Drug Targets 2009;9:888-903.

6. Laoui D, Movahedi K, Van Overmeire E, et al. Tumorassociated macrophages in breast cancer: distinct subsets, distinct functions. Int J Dev Biol 2011;55:861-7.

7. Kudo-Saito C, Shirako H, Ohike M, et al. CCL2 is critical for immunosuppression to promote cancer metastasis. Clin Exp Metastasis 2013;30:393-405.

8. Jafarzadeh A, Minaee K, Farsinejad AR, et al. Evaluation of the circulating levels of IL-12 and IL-33 in patients with breast cancer: influences of the tumor stages and cytokine gene polymorphisms. Iran J Basic Med Sci 2015;18:1189-98.

9. Popa C, Netea MG, van Riel PL, et al. The role of TNFalpha in chronic inflammatory conditions, intermediary metabolism, and cardiovascular risk. J Lipid Res 2007;48:751-62. 
10. Zhang N, Kong X, Yan S, et al. Huaier aqueous extract inhibits proliferation of breast cancer cells by inducing apoptosis. Cancer Sci 2010;101:2375-83.

11. Wang L, Yu Z, Wei C, et al. Huaier aqueous extract protects against dextran sulfate sodium-induced experimental colitis in mice by inhibiting NLRP3 inflammasome activation. Oncotarget 2017;8:32937-45.

12. Li Y, Qi W, Song X, et al. Huaier extract suppresses breast cancer via regulating tumor-associated macrophages. Sci Rep 2016;6:20049.

13. Xu X, Wei Q, Wang K, et al. Anticancer effects of Huaier are associated with down-regulation of P53. Asian Pac J Cancer Prev 2011;12:2251-4.

14. Wu T, Chen W, Liu S, et al. Huaier suppresses proliferation and induces apoptosis in human pulmonary cancer cells via upregulation of miR-26b-5p. FEBS Lett 2014;588:2107-14.

15. Zhao GS, Liu Y, Zhang Q, et al. Transarterial chemoembolization combined with Huaier granule for the treatment of primary hepatic carcinoma: Safety and efficacy. Medicine (Baltimore) 2017;96:e7589.

16. Sun Y, Sun T, Wang F, et al. A polysaccharide from the fungi of Huaier exhibits anti-tumor potential and immunomodulatory effects. Carbohydr Polym 2013;92:577-82.

17. Li C, Wu X, Zhang H, et al. A Huaier polysaccharide reduced metastasis of human hepatocellular carcinoma SMMC-7721 cells via modulating AUF-1 signaling pathway. Tumour Biol 2015;36:6285-93.

18. Wang Y, Liu T, Yang N, et al. Hypoxia and macrophages promote glioblastoma invasion by the CCL4-CCR5 axis. Oncol Rep 2016;36:3522-8.

19. Esquivel-velázquez M, Ostoa-Saloma P, PalaciosArreola MI, et al. The role of cytokines in breast cancer development and progression. J Interferon Cytokine Res 2015;35:1-16.

20. Yoshimura T, Howard OM, Ito T, et al. Monocyte Chemoattractant Protein-1/CCL2 Produced by Stromal Cells Promotes Lung Metastasis of 4T1 Murine Breast Cancer Cells. Plos One 2013;8:e58791.

21. Steiner JL, Davis JM, Mcclellan JL, et al. Effects of the MCP-1 synthesis inhibitor bindarit on tumorigenesis and inflammatory markers in the C3(1)/SV40Tag mouse model of breast cancer. Cytokine 2014;66:60-8.

22. Yoshidome H, Kohno H, Shida T, et al. Significance of monocyte chemoattractant protein-1 in angiogenesis and survival in colorectal liver metastases. Int J Oncol 2009;34:923-30.
23. Bonapace L, Coissieux MM, Wyckoff J, et al. Cessation of CCL2 inhibition accelerates breast cancer metastasis by promoting angiogenesis. Nature 2014;515:130-3.

24. Ito $\mathrm{Y}$, Ishiguro $\mathrm{H}$, Kobayashi $\mathrm{N}$, et al. Adipocyte-derived monocyte chemotactic protein-1 (MCP-1) promotes prostate cancer progression through the induction of MMP-2 activity. Prostate 2015;75:1009-19.

25. Maurer M, von Stebut E. Macrophage inflammatory protein-1. Int J Biochem Cell Biol 2004;36:1882-6.

26. Ren M, Guo Q, Guo L, et al. Polymerization of MIP-1 chemokine (CCL3 and CCL4) and clearance of MIP-1 by insulin-degrading enzyme. EMBO J 2010;29:3952-66.

27. Ishikawa K, Yoshida S, Nakao S, et al. Bone marrowderived monocyte lineage cells recruited by MIP-1 $\beta$ promote physiological revascularization in mouse model of oxygen-induced retinopathy. Lab Invest 2012;92:91-101.

28. Tanyel CR, Cincin ZB, Gokcen-Rohlig B, et al. Effects of genetic variants of CCR5 chemokine receptors on oral squamous cell carcinoma. Genet Mol Res 2013;12:5714-20.

29. Sadeghi M, Lahdou I, Oweira H, et al. Serum levels of chemokines CCL4 and CCL5 in cirrhotic patients indicate the presence of hepatocellular carcinoma. Br J Cancer 2015;113:756-62.

30. Liu JY, Li F, Wang LP, et al. CTL- vs Treg lymphocyteattracting chemokines, CCL4 and CCL20, are strong reciprocal predictive markers for survival of patients with oesophageal squamous cell carcinoma. Br J Cancer 2015;113:747-55.

31. Trellakis S, Bruderek K, Dumitru CA, et al. Polymorphonuclear granulocytes in human head and neck cancer: enhanced inflammatory activity, modulation by cancer cells and expansion in advanced disease. Int J Cancer 2011;129:2183-93.

32. Baghel KS, Tewari BN, Shrivastava R, et al. Macrophages promote matrix protrusive and invasive function of breast cancer cells via MIP-1 $\beta$ dependent upregulation of gene in breast cancer cells. Oncoimmunology 2016;5:e1196299.

33. Li C, Wu X, Zhang H, et al. A Huaier polysaccharide restrains hepatocellular carcinoma growth and metastasis by suppression angiogenesis. Int J Biol Macromol 2015;75:115-20.

34. Vajdic CM, van Leeuwen MT. Cancer incidence and risk factors after solid organ transplantation. Int J Cancer 2009;125:1747-54.

35. Ray-Coquard I, Cropet C, Van Glabbeke M, et al. Lymphopenia as a prognostic factor for overall survival in advanced carcinomas, sarcomas, and lymphomas. Cancer 
Res 2009;69:5383-91.

36. Gaspar HB, Cooray S, Gilmour KC, et al. Long-term persistence of a polyclonal $\mathrm{T}$ cell repertoire after gene therapy for X-linked severe combined immunodeficiency. Sci Transl Med 2011;3:97ra79.

37. Buckley RH. Molecular defects in human severe combined immunodeficiency and approaches to immune reconstitution. Annu Rev Immunol 2004;22:625-55.

38. Sportès C, Babb RR, Krumlauf MC, et al. Phase I study of recombinant human interleukin-7 administration in subjects with refractory malignancy. Clin Cancer Res 2010;16:727-35

39. Yuan CH, Yang XQ, Zhu CL, et al. Interleukin-7 enhances the in vivo anti-tumor activity of tumor-reactive CD8+ $T$ cells with induction of IFN-gamma in a murine breast cancer model. Asian Pac J Cancer Prev 2014;15:265-71.

40. Elkassar N, Gress RE. An overview of IL-7 biology and its use in immunotherapy. J Immunotoxicol 2010;7:1-7.

41. Lundström W, Fewkes NM, Mackall CL. IL-7 in human health and disease. Semin Immunol 2012;24:218-24.

42. Cha E, Graham L, Manjili MH, et al. IL-7 + IL-15 are superior to IL-2 for the ex vivo expansion of 4T1 mammary carcinoma-specific $T$ cells with greater efficacy against

Cite this article as: Zhang L, Zhang N, Qu X, Li Y, Yang Q. Huaier extract exerts immunomodulatory effects by regulating serum cytokines in breast cancer. Transl Cancer Res 2018;7(4):947-957. doi: 10.21037/tcr.2018.06.22 tumors in vivo. Breast Cancer Res Treat 2010;122:359-69.

43. Le HK, Graham L, Miller CH, et al. Incubation of antigen-sensitized $\mathrm{T}$ lymphocytes activated with bryostatin $1+$ ionomycin in IL-7 + IL-15 increases yield of cells capable of inducing regression of melanoma metastases compared to culture in IL-2. Cancer Immunol Immunother 2009;58:1565-76.

44. Miller PW, Sharma S, Stolina M, et al. Intratumoral administration of adenoviral interleukin 7 genemodified dendritic cells augments specific antitumor immunity and achieves tumor eradication. Hum Gene Ther 2000;11:53-65.

45. Al-Rawi MA, Rmali K, Mansel RE, et al. Interleukin 7 induces the growth of breast cancer cells through a wortmannin-sensitive pathway. Br J Surg 2004;91:61-8.

46. Ming J, Jiang G, Zhang Q, et al. Interleukin-7 up-regulates cyclin D1 via activator protein-1 to promote proliferation of cell in lung cancer. Cancer Immunol Immunother 2012;61:79-88.

47. Qu H, Zou Z, Pan Z, et al. IL-7/IL-7 receptor axis stimulates prostate cancer cell invasion and migration via $\mathrm{AKT} / \mathrm{NF}-\kappa \mathrm{B}$ pathway. Int Immunopharmacol 2016;40:203-10. 